\title{
A Cell Model for Conditional Profiling of Androgen-Receptor-Interacting Proteins
}

\author{
K. A. Mooslehner, J. D. Davies, and I. A. Hughes \\ Department of Paediatrics, Addenbrooke's Hospital, University of Cambridge, Level 8, Box 116, Hills Road, \\ Cambridge CB2 OQQ, UK \\ Correspondence should be addressed to K. A. Mooslehner, kam53@medschl.cam.ac.uk
}

Received 7 September 2011; Revised 2 November 2011; Accepted 7 November 2011

Academic Editor: Olaf Hiort

Copyright $\odot 2012$ K. A. Mooslehner et al. This is an open access article distributed under the Creative Commons Attribution License, which permits unrestricted use, distribution, and reproduction in any medium, provided the original work is properly cited.

\begin{abstract}
Partial androgen insensitivity syndrome (PAIS) is associated with impaired male genital development and can be transmitted through mutations in the androgen receptor (AR). The aim of this study is to develop a cell model suitable for studying the impact AR mutations might have on AR interacting proteins. For this purpose, male genital development relevant mouse cell lines were genetically modified to express a tagged version of wild-type AR, allowing copurification of multiprotein complexes under native conditions followed by mass spectrometry. We report 57 known wild-type AR-interacting proteins identified in cells grown under proliferating and 65 under nonproliferating conditions. Of those, 47 were common to both samples suggesting different AR protein complex components in proliferating and proliferation-inhibited cells from the mouse proximal caput epididymus. These preliminary results now allow future studies to focus on replacing wild-type AR with mutant AR to uncover differences in protein interactions caused by AR mutations involved in PAIS.
\end{abstract}

\section{Background}

Androgen insensitivity gives rise to a wide spectrum of disorders in man, the most severe being complete sex reversal, to milder forms of PAIS associated with ambiguous or underdeveloped genitalia, or even milder forms causing "only" male infertility in otherwise healthy males. Often mutations in the androgen receptor (AR) are involved which interfere with ligand binding, DNA binding, or increase or decrease intramolecular interactions between AR domains [1]. Where no mutations are identified in the AR [2] mutations in AR coregulators may be implicated in failure to activate or repress androgen-regulated target genes. Although there are a number of mouse models available to study impaired AR function in vivo [3], the signalling networks are too complex to dissect without using simpler cell models. The aim of this study was to develop a cell model for the study of AR signalling in the urogenital tract. In turn this may identify disrupted signalling resulting from AR mutations associated with PAIS. Male genital development relevant murine cell lines PC1 (proximal caput epithelial cells from mouse epididymus) [4] and MFVD (mesenchymal fetal vas deferens cells) [5] were genetically modified to express a tagged wild-type AR to test the system. The modifications allow purification of multiprotein complexes associated with AR under native conditions and analysis of the copurified protein complexes by mass spectrometry. The data was analysed using readily available bioinformatics software: the pathway mining tool of "DAVID" bioinformatics resources $[6,7]$ and the gene group functional profiling tool of $\mathrm{g}$ : profiler [8]. By focussing solely on known AR coregulators, we were able (as a proof of principle) to uncover differences in the proteome of proliferating and nonproliferating epithelial PC1 cells.

\section{Methods}

2.1. N-Terminal Tandem Affinity Purification Tag (N-TAP). The N-TAP was designed by modifying the C-terminal tandem affinity tag (C-TAP) from Fernández et al., 2009 [9]. The HAT tag was amplified, using the C-terminal tag [9] as a template and PCR primers (Figure 1(a)) designed to add 
1 GCCGAAGCUUAUCGAGAAUUUGUAUUUUCAGGGGGAAUUACCAACAGCAGCAAAGGAUCA

F 5'- GCCGAAGCTTATCGAGAAT TTGTATTTTCAGGGGGAATTACCAACAGCAGCAAAGGATCA
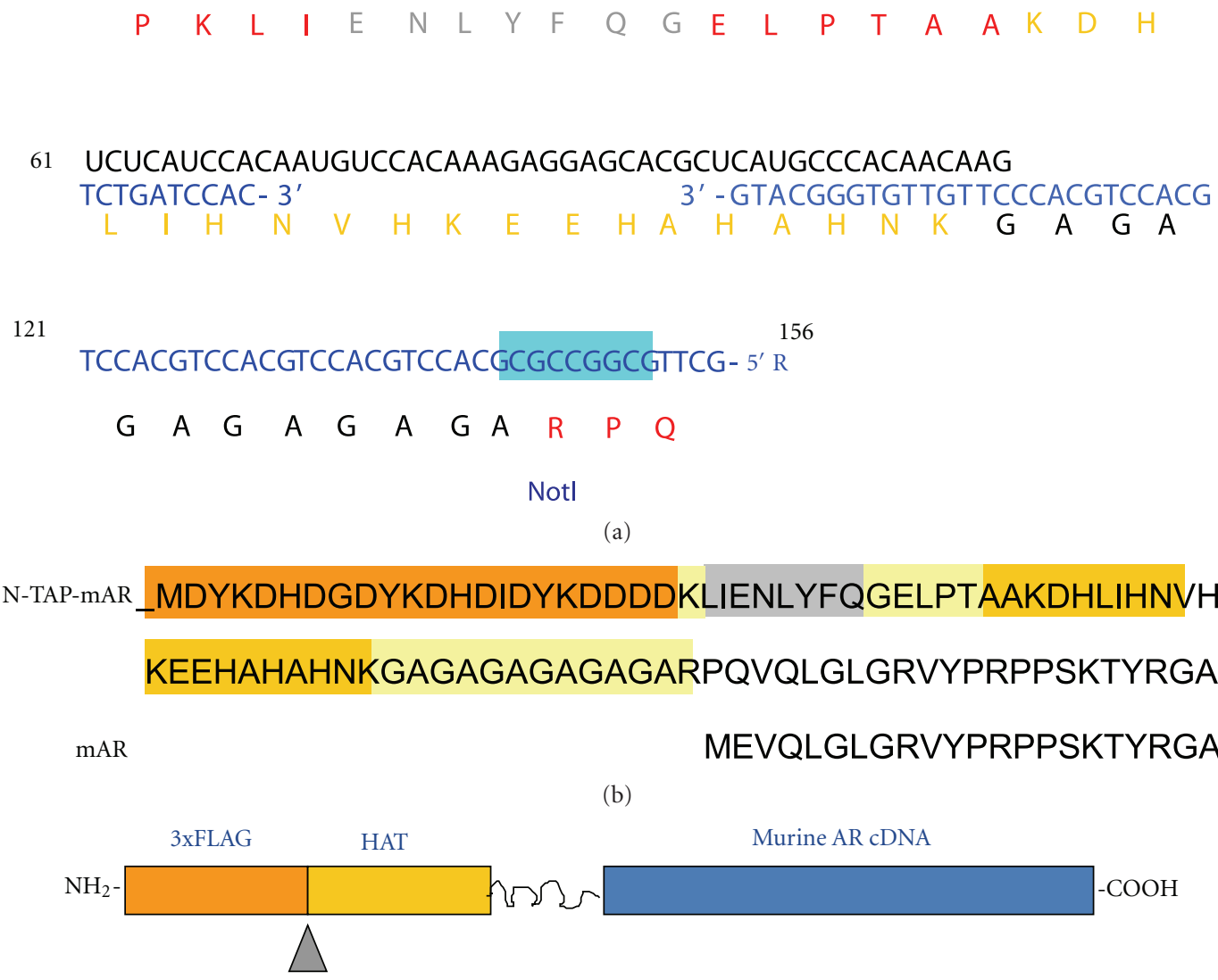

Protease sites

Flexible linker Tobacco etch virus gly-Ala Enterokinase

(c)

FIgURE 1: Creation of the mouse N-TAP-mAR. (a) Amplification of the TEV-HAT-glycine alanine repeat sequence with primers F and R using the C-TAP from Fernández et al., 2009 [9] as template. (b) Aminoacid sequence of the complete NH2-terminus of the androgen receptor. The N-TAP increases the size of the mAR by 70 amino acids and the molecular weight by $7.8 \mathrm{kDa}$ (http://web.expasy.org/compute_pi/). (c) Schematic showing the tagged androgen receptor (N-TAP-mAR) cDNA clone. The N-terminal TAP tag was selected on the basis of small size. It contains three FLAG epitopes (3xFLAG) and 6xHistidine residues (HAT) located in an alpha helix.

the TEV protease cleavage site with the forward primer and the glycine-alanine repeat and an additional NotI-cloning site with the reverse primer. The HindIII-NotI fragment was then inserted into the polylinker region of p3XFLAGCMV-10 (Sigma) in frame with 3XFLAG (Figure 1(b)). The mouse androgen receptor cDNA clone (gift from Professor Jan Trapman, Department of Pathology, Erasmus MC/JNI Rotterdam) was modified by replacing the start methionine ATG with an NotI site-by-site directed mutagenesis (Stratagene) and introducing the $2.787 \mathrm{~kb}$ NotI-BHI full length mouse cDNA into the N-TAP-CMV-10 vector (Figure $1(\mathrm{c})$ ). The N-TAP-mAR fusion construct was confirmed by sequencing.
2.2. Transient Transfection and Luciferase Assay. In total $10^{5}$ COS-1 or Hela cells/well were seeded into 12-well tissue culture plates in DMEM, containing 10\% charcoalstripped serum. Cells were transiently transfected using Fugene (Roche) or Lipofectamine 2000 (Invitrogen) with $25 \mathrm{ng}$ AR or N-TAP-mAR, $500 \mathrm{ng}$ of pGRE-luciferase and $25 \mathrm{ng}$ pTK-RL according to manufacturer's instructions. 12-16 hours after transfection, the medium was replaced with DMEM, containing 10\% charcoal-stripped serum + or $-10 \mathrm{nM}$ dihydrotestosterone (DHT; Sigma). $24 \mathrm{~h}$ later, cells were harvested and lysed in $25 \mathrm{mM}$ glycine ( $\mathrm{pH} 7.8$ ), $15 \mathrm{mM} \mathrm{MgSO} 4,4 \mathrm{mM}$ EGTA, $1 \%$ triton $\times 100$ and $1 \mathrm{mM}$ dithiothreitol. Luciferase assays 
were performed with reagents from nanolight technology and the ratio of luciferin: renillaluciferase activity was measured using a Turner TD-20/20 luminometer. Standard error bars relate to three independent transfection experiments.

2.3. Control Cell Lines. Androgen responsive cell lines PC1 and MFVD from the mouse urogenital tract served as control cell lines in their nonmodified state. The PC 1 cell line was a gift from Araki et al. [4] and the MFVD cell line a gift from Umar et al. [5]. The PC1 cell line is an epididymal cell line immortalized with SV 40 large T-antigen and has been characterized in great detail regarding morphology [4], epithelial and epididymus specific gene expression [4], and androgen responsiveness [10]. Also the MFVD cell line is immortalized by expression of a temperature sensitive SV 40 large T-antigen but of mesenchymal origin. MFVD cells were derived from fetal (18 d.p.f.) mouse vas deferens and show features of Wolffian duct mesenchymal cells and androgen responsiveness [5]. Both cell lines were continuously cultured under conditions given elsewhere $[4,5]$ in the presence of $5 \mathrm{nM}$ mibolerone, a synthetic androgen.

2.4. Establishment of Stable Cell Lines. The control cell lines PC1 and MFVD were transfected with the ScaI (unique site in the bacterial ampicillin resistance) linearised N-TAPmAR vector using Lipofectamine 2000 (Invitrogen). After 48 hours, transfected cells were replated in dilutions from $10^{5}-10^{3}$ cells/ $14 \mathrm{~cm}$ diameter dish and G418 resistant clones were selected with $750 \mu \mathrm{g} / \mathrm{mL}$ G418 (PC1) and $250 \mathrm{ug} / \mathrm{mL}$ G418 (MFVD). Single colonies coming up were picked with cloning rings, grown up and tested for N-TAP-mAR expression by Western blot analysis and immunocytochemistry using the FLAG M2 antibody (Sigma) and the AR-N20 antibody (Santa Cruz).

2.5. Growth of Proliferating and Nonproliferating PC1 and P17 Cells. PC1 cells, derived from the mouse proximal caput epididymus and immortalized by expression of a temperature sensitive SV 40 large T-antigen, were continuously cultured at $33^{\circ} \mathrm{C}$, the permissive temperature of large $\mathrm{T}$ in the presence of $5 \mathrm{nM}$ mibolerone. At physiological temperature $\left(37^{\circ} \mathrm{C}\right)$, cell growth is partly inhibited and T-antigen-expressing cells can survive [11]. Large $\mathrm{T}$ is however degraded after prolonged exposure of the cells to the nonpermissive temperature $\left(39^{\circ} \mathrm{C}\right)$, then significant cell death occurs and the cells do not recover [11]. To prevent cell death but still have an inhibitory effect on proliferation early passage $\mathrm{PC} 1$ and $\mathrm{P} 17$ cells were cultured to near confluence at $33^{\circ} \mathrm{C}$ and kept then for 1 week at $37^{\circ} \mathrm{C}$ in growth medium containing $5 \mathrm{nM}$ mibolerone before preparing cytoplasmic and nuclear extracts of the still healthy looking cells. For extracts made from proliferating PC1 and $\mathrm{P} 17$ cells, the cells were grown at $33^{\circ} \mathrm{C}$ in growth medium containing $5 \mathrm{nM}$ mibolerone. Similar amounts of cell pellets from proliferating and nonproliferating cells were processed for protein extraction.
2.6. Immunoblotting. Cells from subconfluent cultures were washed, trypsinized, and pelleted by centrifugation and washed $3 \mathrm{x}$ in cold PBS. For whole cell lysates, cells were lysed in SDS loading buffer $(0.03125 \mathrm{M}$ Tris $\mathrm{pH} 6.8,5 \%$ glycerol, $0.001 \%$ bromphenol blue 3, $1 \%$ SDS, $2.5 \% \beta$ mercaptoethanol). Samples were subjected to sodium dodecyl sulphate-polyacrylamide gel electrophoresis (SDSPAGE), transferred to polyvinylidene difluoride membrane, blocked and probed in phosphate-buffered saline $(150 \mathrm{mM}$ $\mathrm{NaCl}, 3 \mathrm{mM} \mathrm{KCl}, 10 \mathrm{mM}$ phosphate salts (mono and dibasic) (pH 7.3), $0.05 \%$ (vol/vol) Tween 20) containing 10\% nonfat dry milk. Primary antibodies were used at recommended dilutions and horseradish peroxidase-conjugated secondary antibodies (Dako) and ECL Plus Blotting Detection Reagents (Amersham) or SuperSignal West Femto (Thermo Scientific) were used as described in the manufacturer's instructions. SRC-1 (128E7) and CTNNB1 (9587) antibodies were purchased from NEB, FLAG M2 (F3165) from Sigma, and N20-AR (Sc-816), NR3C1 (Sc-8992), SMARCC1 (Sc-9748), ACTB (Sc-81178) from Santa Cruz.

2.7. Cytoplasmic and Nuclear Protein Extraction and Purification of N-TAP-mAR. The protein extraction protocol is a modified version of a chromatin extraction protocol for copurification of histones by Saade et al., 2009 [12]. Cells were grown on $14 \mathrm{~cm}$ diameter dishes to confluence (10 plates PC1 or 20 plates $\mathrm{P} 17$ gave about $700 \mu \mathrm{L}$ cell volume), washed $3 \mathrm{x}$ with prewarmed PBS, trypsinised with $1 \mathrm{~mL}$ trypsin-EDTA (Sigma)/plate 5 minutes $37^{\circ} \mathrm{C}$, inactivated with medium, pooled in $50 \mathrm{~mL}$ Falcon, spun $1200 \mathrm{rpm} 5 \mathrm{mins}$ RT, and washed $3 \mathrm{x}$ with cold $\left(4^{\circ} \mathrm{C}\right)$ PBS. Cells were transferred to a $2 \mathrm{~mL}$ microfuge tube and pelleted by centrifugation at $6500 \mathrm{rpm} 2-3$ minutes at $4^{\circ} \mathrm{C}$. Pellets $(2 \times 200 \mu \mathrm{L})$ were resuspended in $2 \times 1.8 \mathrm{~mL}$ hypotonic buffer $(10 \mathrm{mM}$ Tris $\mathrm{pH} 7.5,10 \mathrm{mM} \mathrm{KCl}, 1.5 \mathrm{mM} \mathrm{MgCl}, 0.1 \%$ Triton, $4.5 \mathrm{mM} \beta$ mercaptoethanol, protease inhibitor cocktail (Roche), $5 \mathrm{nM}$ mibolerone, $1 \mathrm{mM}$ Pefabloc (Roche), and Phosstop (Roche)) by pipetting up and down and vortexing vigorously on highest setting for 15 seconds followed by 45 minute incubation on ice vortexing every 10 minutes. Nuclei were spun down at $4^{\circ} \mathrm{C} 13.000$ RPM for 5 minutes, the supernatant, called here cytosol fraction, transferred to a clean tube and $\mathrm{NaCl}$ was added to $15 \mathrm{mM}$. This cytosol fraction was added to FLAGM2 coupled magnetic beads (ca. $5 \mathrm{mg}$ ) after keeping an aliquot as cytosol input fraction for PAGE. Coupling of the magnetic beads (Dynabeads M-270 Epoxy from Invitrogen) to the FLAG M2 antibody (Sigma F3165) was performed according to manufacturer's instructions. Cytosol extracts on beads rotated for 1 hour minimum at $4^{\circ} \mathrm{C}$. Nuclei were taken up in sucrose buffer $(0.34 \mathrm{M}$ sucrose, $10 \mathrm{mM}$ Tris $\mathrm{pH} 8,3 \mathrm{mM} \mathrm{MgCl} 2,1 \mathrm{mM} \mathrm{CaCl}, 150 \mathrm{mM} \mathrm{NaCl}, 1 \mathrm{mM}$ DTT, protease inhibitor cocktail (Roche), $5 \mathrm{nM}$ mibolerone, $1 \mathrm{mM}$ Pefabloc (Roche), Phosstop (Roche)) $150 \mu \mathrm{L} / 100 \mu \mathrm{L}$ cell pellet and resuspended. 0.3 units micrococcal nuclease from Sigma $(0.1 \mathrm{U} / \mu \mathrm{L}$ in $10 \mathrm{mM}$ Tris/ $0.1 \mathrm{mM} \mathrm{CaCl} 2 \mathrm{pH} 8)$ for $100 \mu \mathrm{L}$ nuclear extract were added and incubated for $30 \mathrm{~min}$ at $37^{\circ} \mathrm{C}$. Extracts were then diluted with 1 volume of sucrose buffer and sonicated $6 \times 10$ seconds on ice with 
$10 \mathrm{sec}$ bursts and $10 \mathrm{sec}$ cool downs alternating. Extracts were finally loaded onto FLAG M2-coupled magnetic beads and rotated for at least 1 hour at $4^{\circ} \mathrm{C}$ in cold room. Supernatants were kept as flow through and aliquots before loading on to the beads as nuclear input. After the incubation period, beads loaded with cytosol preparations were washed $3 \mathrm{x}$ with hypotonic wash buffer $(10 \mathrm{mM}$ Tris $\mathrm{pH} 7.5,10 \mathrm{mM} \mathrm{KCl}$, $1.5 \mathrm{mM} \mathrm{MgCl}, 0.1 \%$ Triton, $4.5 \mathrm{mM} \beta$-mercaptoethanol, protease inhibitor cocktail (Roche), $5 \mathrm{nM}$ mibolerone, $1 \mathrm{mM}$ Pefabloc (Roche) and Phosstop (Roche), 0.5\% NP40, 0.05\% sodium deoxycholate, $0.005 \%$ SDS, $15 \mathrm{mM} \mathrm{NaCl}$ ) or sucrose buffer (nuclear preps) followed by 3 washes with TEV buffer $(0.05 \mathrm{M}$ Tris $\mathrm{pH} 8,1 \mathrm{mM}$ DTT, $0.5 \mathrm{mM}$ EDTA) supplemented with Protease Inhibitor Cocktail (Roche), mibolerone $(5 \mathrm{nM})$, and phosphatase inhibitors (Phosstop and Pefabloc (Roche), and $\mathrm{NaCl}$ to $15 \mathrm{mM} \mathrm{NaCl}$ in cytosolic and $150 \mathrm{mM} \mathrm{NaCl}$ in nuclear TEV buffer. The beads were finally taken up in $100 \mathrm{uL}$ TEV buffer and bound protein complexes were eluted with 10 units of TEV protease (GST-tag) (TEVP US Biological) at RT for 1 hour. Protein concentration in the eluted fraction was determined by Bradford assay. The beads were kept in PBS for recycling.

2.8. Mass Spectrometry. Colloidal coomassie stained protein bands (Colloidal Blue Staining Kit, Invitrogen) were excised out of a 5\% PAGE after separation in 7 slices covering a size spectrum of $48 \mathrm{kDa}$ to the top of the gel. Gel slices were briefly washed in MilliQ water and kept in water at $-80^{\circ} \mathrm{C}$ until submitted to "Cambridge Proteomics Services" where all LC-MS/MS experiments were performed using an Eksigent NanoLC-1D Plus (Eksigent Technologies, Dublin, CA) HPLC system and an LTQ Orbitrap Velos mass spectrometer (ThermoFisher, Waltham, MA). Separation of peptides was performed by reverse-phase chromatography used at a flow rate of $300 \mathrm{~nL} / \mathrm{min}$ and an LC-Packings (Dionex, Sunnyvale, CA) PepMap 100 column $(\mathrm{C} 18,75 \mu \mathrm{M}$ i.d. $\times 150 \mathrm{~mm}$, $3 \mu \mathrm{M}$ particle size). Peptides were loaded onto a precolumn (Dionex Acclaim PepMap $100 \mathrm{C} 18,5 \mu \mathrm{M}$ particle size, 100A, $300 \mu \mathrm{M}$ i.d. $\times 5 \mathrm{~mm}$ ) from the autosampler with $0.1 \%$ formic acid for 5 minutes at a flow rate of $10 \mu \mathrm{L} / \mathrm{min}$. After this period, the valve was switched to allow elution of peptides from the precolumn onto the analytical column. Solvent A was water $+0.1 \%$ formic acid and solvent B was acetonitrile $+0.1 \%$ formic acid. The gradient employed was $5-50 \% \mathrm{~B}$ in 45 minutes. The LC eluant was sprayed into the mass spectrometer by means of a new objective nanospray source. All $\mathrm{m} / \mathrm{z}$ values of eluting ions were measured in an Orbitrap Velos mass analyzer, set at a resolution of 30000 . Data dependent scans (Top 20) were employed to automatically isolate and generate fragment ions by collision-induced dissociation in the linear ion trap, resulting in the generation of MS/MS spectra. Ions with charge states of $2+$ and above were selected for fragmentation.

2.9. Data Processing and Database Searching. After run, the data were processed using Protein Discoverer (version 1.2., ThermoFisher). Briefly, all MS/MS data were converted to mgf (text) files. These files were then submitted to the Mascot search algorithm (Matrix Science, London UK) and searched against Uniprot Mouse database, using a fixed modification of carbamidomethyl and variable modifications of oxidation (M).

\section{Results}

3.1. Isolation of N-TAP-mAR Complex in MFVD and PC1 Cell Lines. Stable MFVD and PC1 clones expressing NTAP-mAR were developed as described in Section 2. Total protein was extracted from several clones and analyzed for N-TAP-mAR expression by Western blot using FLAG and AR-specific antibodies (data not shown). A second criteria was the nuclear localization of N-TAP-mAR, which was examined in several clones by immunofluorescence using FLAG and AR-specific antibodies. One MFVD cell line (M7) and one PC1 cell line (P17) were selected on the basis that they expressed similar levels of stably integrated $\mathrm{N}$ TAP-mAR and endogenous wild-type AR (WT AR). Both were predominantly located in the nucleus when grown in medium supplemented with $5 \mathrm{nM}$ mibolerone (Figure 2(a)). The transactivation properties of N-TAP-mAR were tested in COS cells by cotransfection of a GRE reporter construct, with expression levels confirmed by Western blot (Figures 2(b) and 2(c)). Levels of expression are stable, allowing considerable grow up of cells.

Different protein purification protocols for producing nuclear and cytosol cell extracts were tested. Commercially available purification kits and a modified version of a chromatin purification protocol (FLAG-antibody capture) were compared and the latter was chosen. FLAGantibody capture gave a good recovery of N-TAP-mAR when preparing extracts from M7 (Figure 3(a)) or P17 cells (Figure 3(b)). The known coregulators SRC-1 and CTNNB1 were copurified in P17 extracts but not in M7 extracts. Attempts to optimize His-tag purification conditions were unsuccessful; Nickel affinity purification of the PC1 (NTAP-mAR negative control) chromatin extracts gave high background with unspecific protein binding to the Nickel resin. The cell lines proliferate at $33^{\circ} \mathrm{C}$ with growth driven by temperature sensitive SV40 T-antigen; and proliferation stops at $37^{\circ} \mathrm{C}$. Figure 3 (c) illustrates a preparative gel of TEV protease-eluted proteins purified from the nuclei of P17 cells cultured at $33^{\circ} \mathrm{C}$ and $37^{\circ} \mathrm{C}$. The gel slices were selected for LC- MS/MS, and data processed using the Mascot Search engine at the Cambridge Centre for Proteomics.

The results from the LC-MS/MS search are portrayed as peptide matches and grouped as protein hits using a simple parsimony algorithm (http://www.matrixscience.com/). Only those ions scores that exceed a significance threshold of 0.05 ( 1 in a 20 chance of being a false positive) contributed to the score. This would translate into 1500 peptides falling within the mass tolerance window to have a score of $\geq 45$. Known AR-interacting proteins (http://androgendb.mcgill.ca) were identified among the protein hits and are listed in Table 1 along with their respective peptide scores. In this first mass spec analysis, we identified 1196 AR associated proteins in FLAG purified 

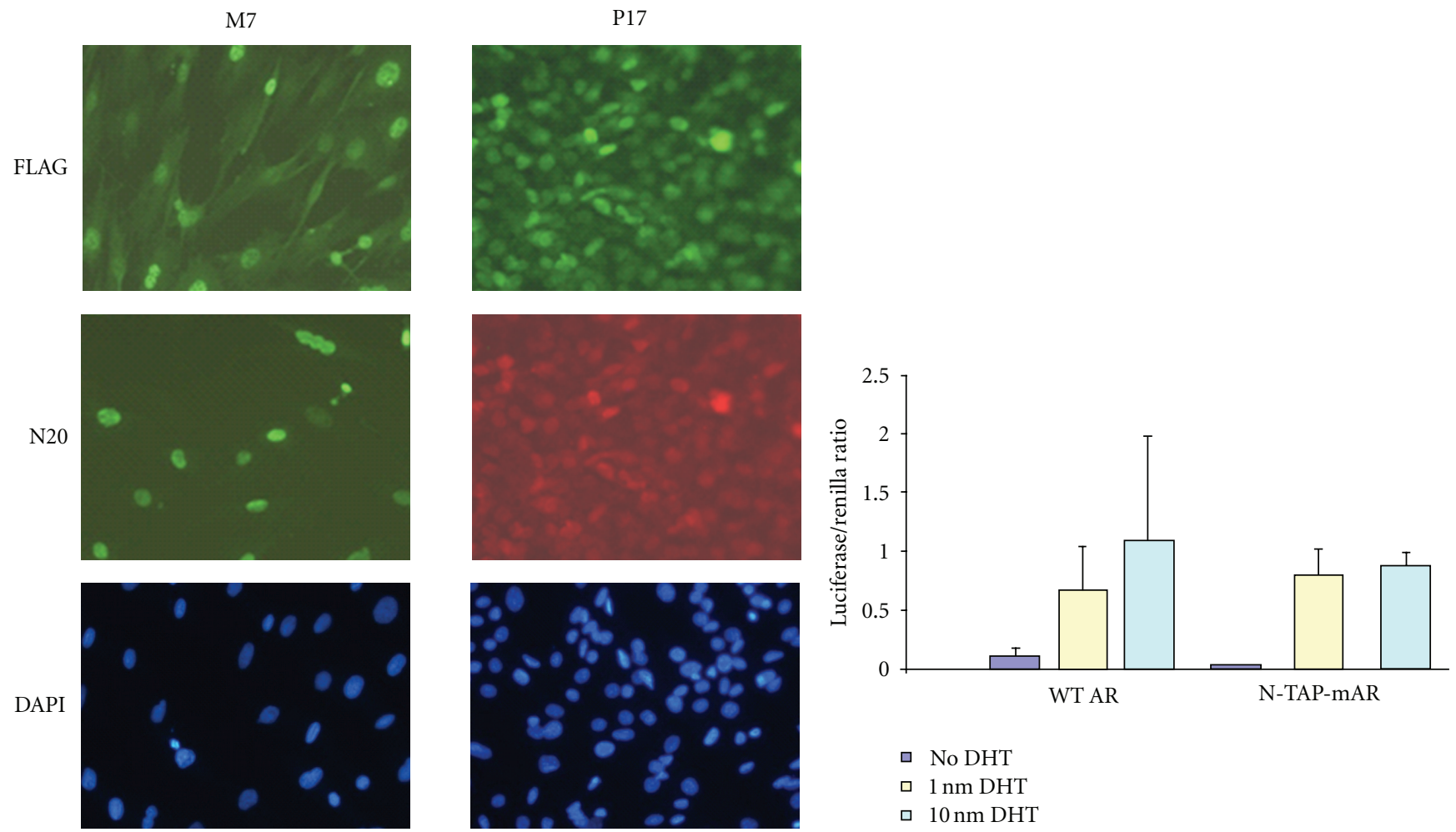

(a)

(b)

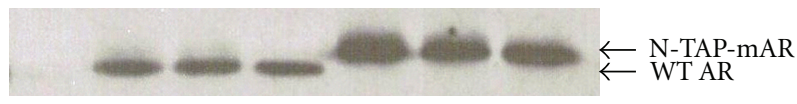

(c)

Figure 2: Nuclear localization and transactivation ability of N-TAP-mAR. (a) Immunostaining of a stable mesenchymal cell line M7 and a stable epithelial cell line P17 expressing N-TAP-mAR. The FLAG antibody detects tagged androgen receptor only. N20 antibody recognises both endogenous AR and N-TAP-mAR. Nuclei staining with DAPI indicates the percentage of cells expressing NTAP-mAR. (b) The ability of the modified N-TAP-mAR and WT-AR to activate a glucocorticoid response element (GRE) was assayed in COS- 1 cells in a transient transfection luciferase assay. GRE promoter activation, shown here on the $y$-axis as luciferase/renilla ratio, was similar for the tagged and nontagged androgen receptor. (c) Tagged androgen receptor expression (N-TAP-mAR) was elevated in the Western blot done with protein extracts from the transactivation samples relative to WT.

extract from proliferating cells and 1456 from nonproliferating cells. Of those 882 were common between those two groups, 314 were only picked up in FLAG purifications from proliferating cells and 574 were only picked up in FLAG purifications from nonproliferating cells. Functional profiling was carried out using web tools "DAVID" $[6,7]$ and "g:profiler" [8], providing functional enrichments in the form of pathways, biological processes, molecular functions, metabolic functions, cellular localization, protein-protein interactions, and shared transcription factor binding sites. Only pathways and biological processes which received the highest scores are utilized.

\subsection{Analysis of Gene Lists with DAVID Bioinformatics Resources [6, 7].}

$37^{\circ} \mathrm{C}$. The gene list of known AR-interacting proteins identified in the nuclear FLAG purifications of the $37^{\circ} \mathrm{C}$ samples
(37 only + common, Table 1) was accepted as 65 DAVID ID's using DAVID bioinformatics resources [6,7]. Gene ontology tool "GOTERM_BP_FAT" gives the highest score to the biological process (BP) "regulation of transcription" with 40 contributing genes (Table 2). Another high scoring biological process "chordate embryonic development" listed 11 genes: NCOR2, SMARCA4, AR, PSMC3, PRKDC, KDM1A, TRP53, and EP300 common to both temperatures and MED1, NF1, and SP1 specific to the $37^{\circ} \mathrm{C}$ samples (Table 4). When analyzing the gene list for pathways, 10 genes are components of the Kegg Pathway: pathways in cancer: EP300, AR, CTNNB1, DAPK3, HSP90, PIAS1, RB1, STAT3, HDAC1, and TRP53. Of these 10 genes only STAT3, RB1, and DAPK3 have inhibitory function in this pathway. 6 of those 10 genes (EP300, AR, CTNNB1, Hsp90, RB1, and TRP53) have been associated with prostate cancer (Table 3 ).

The BIOCARTA Chart revealed overrepresented pathways: "telomeres, telomerase, cellular aging, and immortality", with 5 genes (XRCC5, XRCC6, HSP90, RB1, and 


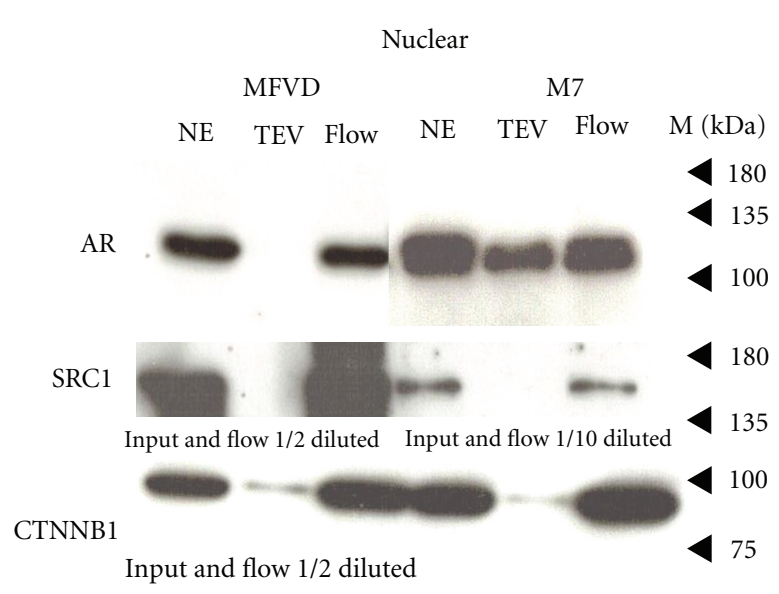

(a)

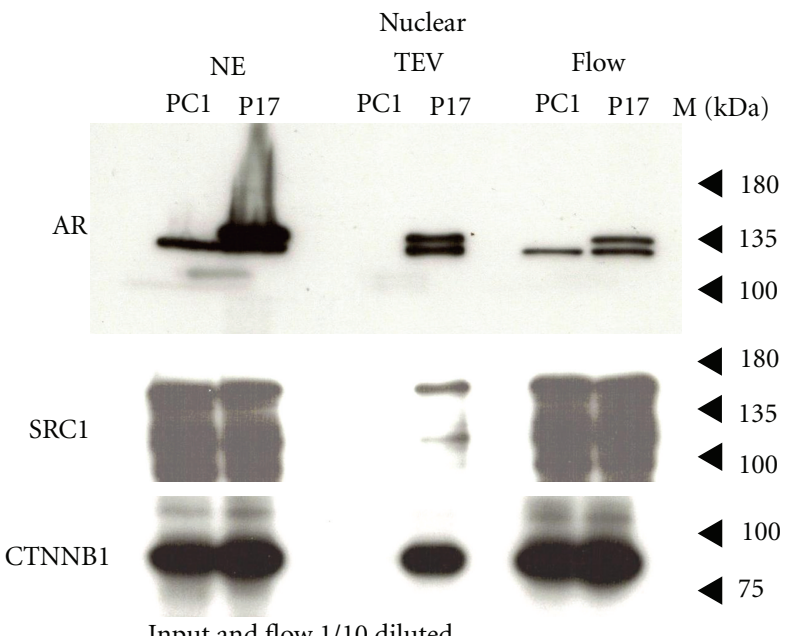

Input and flow $1 / 10$ diluted

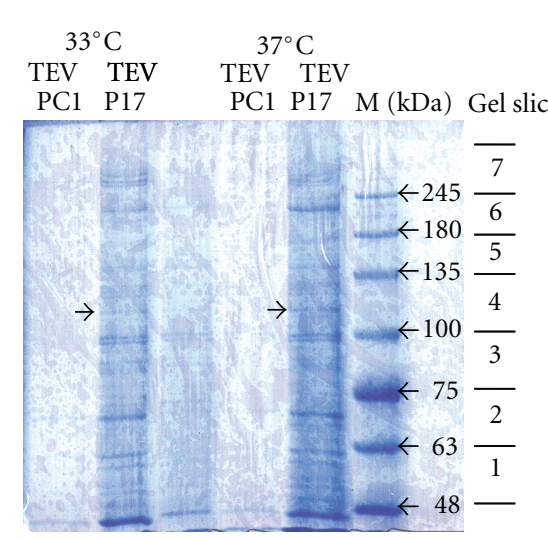

(c)

(b)

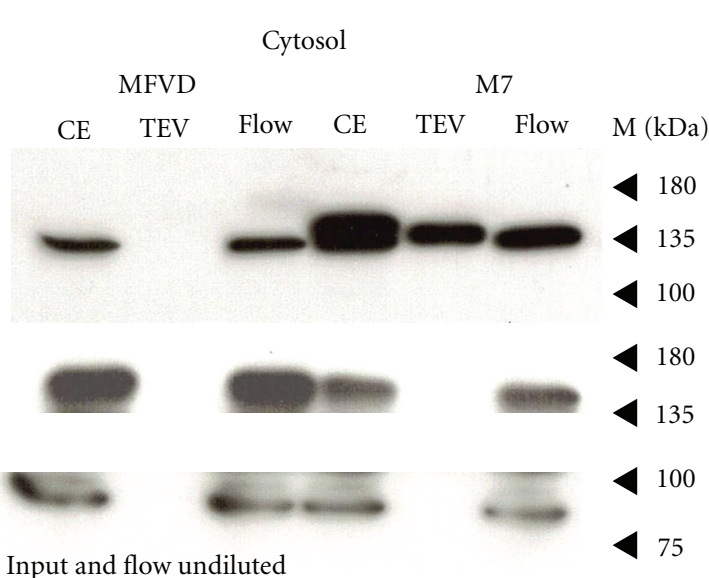

Input and flow undiluted

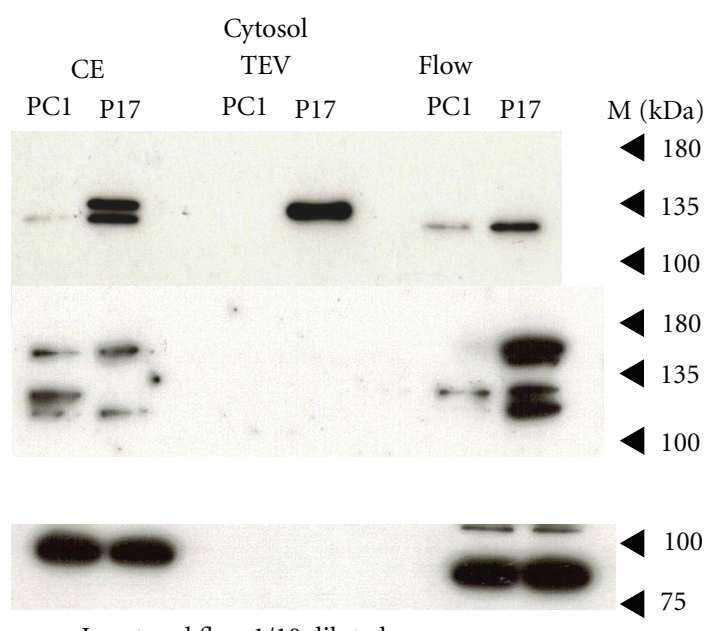

Input and flow 1/10 diluted 
TABLE 1: List of only the known androgen-receptor-interacting proteins and coregulators (http://androgendb.mcgill.ca) identified after mass spec analysis of all gel fractions (Figure 3(a)) from FLAG purifications of nuclear extracts from P17 cells grown under proliferating and nonproliferating conditions (see Section 2). (a) Listed are the interacting proteins that were unique for the proliferating cells (33 only), interacting proteins that were unique for the nonproliferating cells (37 only), and (b) interacting proteins common to both (common). The $\mathrm{AR}$ is highlighted. Given are the Uniprot accession numbers identified by the database Mascot search (Uniprot), the score achieved in the peptide summary report (score), the gel slice number (), and information whether the protein had been identified as a coactivator (CoA), corepressor (coR), or the effect has not been reported (-). Activating function has been allocated to GSN [13, 14], without distinguishing between the 2 isoforms [15].

(a)

\begin{tabular}{|c|c|c|c|c|c|c|c|}
\hline 33 only & $\mathrm{coA} / \mathrm{coR}$ & Score: P17/PC1 (slice) & Uniprot & 37 only & $\mathrm{coA} / \mathrm{coR}$ & Score: P17 (slice) & Uniprot \\
\hline KDM3A & $\mathrm{CoA}$ & $52(3)$ & Q6PCM1 & KDM5B & $\mathrm{coA}$ & $93(5)$ & Q80Y84 \\
\hline WHSC1 & $\mathrm{CoA}$ & $252(5)$ & Q8BVE8 & DAPK3 & $\operatorname{coA}$ & $67(1)$ & O54784 \\
\hline MED17 & $\mathrm{CoA}$ & $66(2)$ & Q8VCD5 & PIAS1 & $\mathrm{coA} / \mathrm{CoR}$ & $38(2)$ & O88907 \\
\hline MED24 & $\mathrm{CoA}$ & $156(3)$ & A6PW47 & MED1 & $\operatorname{coA}$ & $44(6)$ & Q925J9 \\
\hline ARID1B & $\mathrm{CoA}$ & $38(6)$ & E9Q4N7 & GATA3 & $\mathrm{coA}$ & $55(1)$ & P23772 \\
\hline SRC & - & $57(1)$ & Q2M4I4 & SP1 & $\mathrm{coA}$ & $81(3)$ & O89090 \\
\hline SMARCC1 & $\mathrm{CoA}$ & $1112 / 60(5)$ & Q3UNN4 & TGFBI1 & $\mathrm{coA}$ & $32(1)$ & Q62219 \\
\hline SMARCD1 & $\mathrm{CoA}$ & $39(1)$ & Q61466 & TRIM24 & $\operatorname{coA}$ & $165(4)$ & Q64127 \\
\hline NPM1 & $\mathrm{CoA}$ & $438(6)$ & Q5SQB0 & FKBP5 & $\mathrm{coA}$ & $29(1)$ & Q64378 \\
\hline \multirow[t]{9}{*}{ GTF2F1 } & - & $89(2)$ & Q3THK3 & RANBP10 & $\mathrm{coA}$ & $53(2)$ & Q6VN19 \\
\hline & & & & CALCOCO1 & $\mathrm{coA}$ & $156(3)$ & Q8CGU1 \\
\hline & & & & PSPC1 & $\mathrm{coA}$ & $35(2)$ & Q8R326 \\
\hline & & & & GAK & $\mathrm{coA}$ & $397(5)$ & Q99KY4 \\
\hline & & & & NCOA2 & $\mathrm{coA}$ & $68(5)$ & Q61026 \\
\hline & & & & NR3C1 & coR & $97(3)$ & Q06VW2 \\
\hline & & & & AP-1 & $\mathrm{coA} / \mathrm{CoR}$ & $56(2)$ & Q3TXG4 \\
\hline & & & & RB1 & $\mathrm{coA}$ & $55(5)$ & Q3URY9 \\
\hline & & & & NF1 & $\mathrm{CoA}$ & $46(7)$ & Q04690-1 \\
\hline & & & (b & b) & & & \\
\hline \multicolumn{2}{|l|}{ Common } & $\mathrm{coA} / \mathrm{coR}$ & \multicolumn{2}{|c|}{$\begin{array}{c}\text { Score } 33^{\circ} \mathrm{C}: \\
\text { P17/PC1 (slice) }\end{array}$} & \multicolumn{2}{|r|}{ Uniprot } & $\begin{array}{l}\text { Score } 37^{\circ} \mathrm{C}: \\
\text { P17 (slice) }\end{array}$ \\
\hline \multicolumn{2}{|l|}{ STAT3 } & $\mathrm{CoA}$ & \multicolumn{2}{|c|}{$41(3)$} & \multicolumn{2}{|r|}{$\mathrm{P} 42227$} & $90(3)$ \\
\hline DAXX & & CoR & \multicolumn{2}{|r|}{$66(4)$} & \multicolumn{2}{|r|}{ Q3UIV3 } & $70(4)$ \\
\hline ARID1A & & $\mathrm{CoA}$ & \multicolumn{2}{|c|}{$107(5)$} & \multicolumn{2}{|r|}{ A2BH40 } & $78(5)$ \\
\hline$H D A C 1$ & & $\mathrm{CoR}$ & \multicolumn{2}{|c|}{$428 / 52(2)$} & \multicolumn{2}{|r|}{009106} & $251(2)$ \\
\hline BRD7 & & CoR & \multicolumn{2}{|c|}{$169(3)$} & \multicolumn{2}{|r|}{ O88665 } & $50(3)$ \\
\hline HSP90 & & $\mathrm{CoR}$ & \multicolumn{2}{|c|}{$719 / 250(3)$} & \multicolumn{2}{|r|}{ P07901 } & $1089(3)$ \\
\hline \multicolumn{2}{|c|}{ GSN isoform1 [15] } & $\mathrm{CoA} ?$ & \multicolumn{2}{|c|}{$542(4)$} & \multicolumn{2}{|c|}{ P13020-1 } & $516(4)$ \\
\hline \multicolumn{2}{|c|}{ GSN isoform2 [15] } & $C o A ?$ & \multicolumn{2}{|c|}{$1879 / 624(3)$} & \multicolumn{2}{|r|}{ P13020-2 } & $1688(3)$ \\
\hline CALR & & CoR & & $148(1)$ & & P14211 & $612(1)$ \\
\hline HSPA1B & & $\mathrm{CoA}$ & & $434(2)$ & & P17879 & $582(2)$ \\
\hline $\mathrm{AR}$ & & $\mathrm{CoA}$ & & $115(4)$ & & P19091 & $200(4)$ \\
\hline XRCC6 & & $\mathrm{CoA}$ & & $208 / 85(2)$ & & P23475 & $1380(2)$ \\
\hline MCM3 & & $\mathrm{CoA}$ & & $728(3)$ & & P25206 & $1476(3)$ \\
\hline XRCC5 & & $\mathrm{CoA}$ & & $727 / 49(3)$ & & $P 27641$ & $1717(3)$ \\
\hline PA2G4 & & CoR & & $9 / 257(1)$ & & P50580 & $54(1)$ \\
\hline ACTN4 & & CoA/CoR & 314 & 47/3229(3) & & P57780 & $3112(3)$ \\
\hline ACTB & & CoA & & $1386(1)$ & & P60710 & $1106(1)$ \\
\hline DNAJA1 & & CoR & & $173(1)$ & & P63037 & $371(1)$ \\
\hline PRKDC & & $\mathrm{CoA}$ & & $1134(7)$ & & P97313 & $739(7)$ \\
\hline CTNNB1 & & $\mathrm{CoA}$ & & $42 / 44(3)$ & & Q02248 & $242(3)$ \\
\hline SMARCA4 & & $\mathrm{CoA}$ & & $841 / 73(6)$ & & Q3TKT4 & $1449(6)$ \\
\hline
\end{tabular}


(b) Continued.

\begin{tabular}{|c|c|c|c|c|}
\hline Common & $\mathrm{coA} / \mathrm{coR}$ & $\begin{array}{c}\text { Score } 33^{\circ} \mathrm{C}: \\
\text { P17/PC1 (slice) }\end{array}$ & Uniprot & $\begin{array}{l}\text { Score } 37^{\circ} \mathrm{C} \text { : } \\
\text { P17 (slice) }\end{array}$ \\
\hline MYST2 & CoR & $437(2)$ & Q5SVQ0 & $36(2)$ \\
\hline KHDRBS1 & CoR & $137 / 100(2)$ & Q60749 & $274(2)$ \\
\hline DDX5 & CoA & $1099 / 753(2)$ & Q61656 & $1150(2)$ \\
\hline SMARCA2 & $\mathrm{CoA}$ & $727(6)$ & Q6DIC0 & $789(6)$ \\
\hline PPP2R1A & CoR & $433(1)$ & Q76MZ3 & $97(1)$ \\
\hline RBM14 & - & $232 / 201(2)$ & Q8C2Q3 & $373(2)$ \\
\hline COBRA1 & $\mathrm{CoR}$ & $50(6)$ & Q8C4Y3 & $40(6)$ \\
\hline ATAD2 & $\mathrm{CoA}$ & $405(5)$ & Q8CDM1 & $2221(5)$ \\
\hline KIAA1967 & $\mathrm{CoA}$ & $39(4)$ & Q8VDP4 & $92(4)$ \\
\hline SFPQ & $\mathrm{CoA} / \mathrm{CoR}$ & $766 / 446(3)$ & Q8VIJ6 & $490(3)$ \\
\hline PRPF6 & CoA & $259(3)$ & Q91YR7 & $218(3)$ \\
\hline NONO & $\mathrm{CoA} / \mathrm{CoR}$ & $625 / 197(1)$ & Q99K48 & $472(1)$ \\
\hline PELP1 & CoA & $261(5)$ & Q9DBD5 & $504(5)$ \\
\hline SART3 & CoR & $286(4)$ & Q9JLI8 & $863(4)$ \\
\hline NCOR2 & $\mathrm{CoR}$ & $107(7)$ & Q9WU42 & $95(7)$ \\
\hline PSMC3 & $\mathrm{CoA}$ & $148(1)$ & A2AGN7 & $247(1)$ \\
\hline EHMT2 & $\mathrm{CoA}$ & $66(5)$ & A2CG76 & $282(5)$ \\
\hline KDM1A & $\mathrm{CoA}$ & $210(4)$ & A3KG93 & $100(4)$ \\
\hline ZFP318 & CoR & $35(3)$ & B0V2M3 & $30(3)$ \\
\hline EP300 & CoA & $31(7)$ & B2RWS6 & $107(7)$ \\
\hline FLNA & $\mathrm{CoA} / \mathrm{CoR}$ & $6598 / 1307(7)$ & B7FAU9 & $6972(7)$ \\
\hline BRD8 & $\mathrm{CoA}$ & $62(5)$ & Q8R3B7 & $164(5)$ \\
\hline SUPERVILLIN & $\mathrm{CoA}$ & $53 / 44(6)$ & Q8K4L3 & $439(6)$ \\
\hline$D D X 17$ & - & $584 / 336(2)$ & Q3U741 & $645(2)$ \\
\hline HDAC6 & $\mathrm{CoA}$ & $99(4)$ & Q3UG37 & $142(4)$ \\
\hline TRP53 & $\mathrm{CoA}$ & $1026 / 71(1)$ & Q80ZA1 & $1090(1)$ \\
\hline SRCAP & $\mathrm{CoA}$ & $57(7)$ & Q8BKT0 & $82(7)$ \\
\hline
\end{tabular}

TRP53) involved. Another overrepresented pathway "chromatin remodeling by hSWI/SNF ATP-dependent complexes" involves genes SMARCA4, ACTB, NR3C1, NF1, ARID1A. A third overrepresented BIOCARTA pathway is "control of gene expression by vitamin D receptor" with EP300, SMARCA4, MED1, NCOA2, and ARID1A involved (Table 3). All 3 pathways do not include the androgen receptor.

$33^{\circ} \mathrm{C}$. The Gene list of known AR-interacting proteins identified in the nuclear FLAG purifications of the $33^{\circ} \mathrm{C}$ samples (33 only + common, Table 1 ) was accepted as 56 DAVID ID's using DAVID bioinformatics resources [6,7]. ARID1B was not detected as DAVID ID and therefore not included in the analysis. As with the samples from $37^{\circ} \mathrm{C}$, the gene ontology tool "GOTERM_BP_FAT" gives the highest score to the biological process (BP) "regulation of transcription" with 34 contributing genes (Table 2). Looking at overrepresented pathways only 7 AR-interacting proteins are components of the Kegg pathway "pathways in cancer": EP300, AR, CTNNB1, HSP90, STAT3, HDAC1, and TRP53. Proteins $\mathrm{RB} 1, \mathrm{DAPK} 3$, and PIAS1 are not present in the $33^{\circ} \mathrm{C}$ samples
(Table 3). Following on from that, only 5 of those genes have been associated with prostate cancer (EP300, AR, CTNNB1, HSP90, and TRP53) and the inhibitory function of RB1 is missing (Table 3 ).

Again the BIOCARTA Chart brings up as overrepresented pathways: "telomeres, telomerase, cellular aging, and immortality", but here with only 4 genes being involved (XRCC5, XRCC6, HSP90, and TRP53) and RB1 missing. "Chromatin remodeling by hSWI/SNF ATP-dependent complexes" has NR3C1 and NF1 missing and gained 3 new components with ARID1B, SMARCC1, and SMARCD1. SMARCA4, ACTB, and ARID1A are present. The pathway "control of gene expression by vitamin D receptor" has now 5 components present EP300, SMARCA4, but not MED1 and NCOA2 anymore. ARID1A is still present and the 2 new components SMARCC1 and SMARCD1.

3.3. Analysis of Gene Lists with g:Profiler [8]. Identical gene lists submitted to DAVID were also submitted to the gene ontology online tool $\mathrm{g}$ : Profiler for functional characterization. "Regulation of transcription" was not a high scoring biological process" on this occasion, whereas "gene 
TABle 2: Gene lists representing the biological processes (BP) "regulation of transcription" and "gene expression" identified by the bioinformatics tools "DAVID" and "g-profiler" as being overrepresented among the known AR-interacting proteins of the N-TAP-mAR purification. Listed are the interacting proteins, the AR is in bold face, that were unique for the proliferating cells (33), interacting proteins that were unique for the nonproliferating cells (37), and interacting proteins common to both (common).

\begin{tabular}{|c|c|c|c|c|c|}
\hline \multicolumn{3}{|c|}{ Regulation of transcription (BP) DAVID } & \multicolumn{3}{|c|}{ Gene expression (BP) g-profiler } \\
\hline 33 & Common & 37 & 33 & Common & 37 \\
\hline \multirow[t]{3}{*}{ KDM3A } & EP300 & & & EP300 & \\
\hline & SMARCA4 & & & SMARCA4 & \\
\hline & AR & & & $\mathrm{AR}$ & \\
\hline \multirow[t]{2}{*}{ WHSC1 } & & MED1 & WHSC1 & & MED1 \\
\hline & CTNNB1 & & & CTNNB1 & \\
\hline \multirow[t]{3}{*}{ MED17 } & & $\mathrm{NR} 3 \mathrm{C} 1$ & MED17 & & NR3C1 \\
\hline & PRPF6 & & & PRPF6 & \\
\hline & KDM1A & & & KDM1A & \\
\hline \multirow[t]{5}{*}{ MED24 } & & SP1 & MED24 & & SP1 \\
\hline & TRP53 & & & TRP53 & \\
\hline & MYST2 & & & MYST2 & \\
\hline & DDX5 & & SRC & DDX5 & \\
\hline & DAXX & & & DAXX & \\
\hline \multirow[t]{3}{*}{ SMARCC1 } & & GATA3 & SMARCC1 & & GATA3 \\
\hline & RBM14 & & SMARCD1 & RBM14 & \\
\hline & BRD7 & & NPM1 & BRD7 & \\
\hline \multirow[t]{24}{*}{ GTF2F1 } & & CALCOCO1 & GTF2F1 & & CALCOCO1 \\
\hline & EHMT2 & & & EHMT2 & \\
\hline & FLNA & & & FLNA & \\
\hline & & KDM5B & & & KDM5B \\
\hline & NONO & & & NONO & \\
\hline & NCOR2 & & & NCOR2 & \\
\hline & & NCOA2 & & & NCOA2 \\
\hline & PA2G4 & & & PA2G4 & \\
\hline & & $\mathrm{RB} 1$ & & & $\mathrm{RB} 1$ \\
\hline & STAT3 & & & STAT3 & \\
\hline & HDAC1 & & & HDAC1 & \\
\hline & SFPQ & & & SFPQ & \\
\hline & & TRIM24 & & & TRIM24 \\
\hline & HDAC6 & & & PRKDC & \\
\hline & COBRA1 & & & CALR & \\
\hline & ATAD2 & & & XRCC6 & \\
\hline & MCM3 & & & SART3 & \\
\hline & BRD8 & & & & \\
\hline & SMARCA2 & & & & \\
\hline & KHDRBS1 & & & & \\
\hline & ZFP318 & & & & \\
\hline & & TGFB11 & & & \\
\hline & & PSPC1 & & & \\
\hline & & PIAS1 & & & \\
\hline
\end{tabular}


TABLE 3: Top half: gene lists representing the BIOCARTA pathways "telomeres, telomerase, cellular aging, and immortality", "chromatin remodeling by hSWI/SNF ATP-dependent complexes" and "control of gene expression by vitamin D receptor" found to be overrepresented among the known AR-interacting proteins identified in the N-TAP purifications by the bioinformatics tool DAVID. Bottom half: gene lists representing the "Kegg pathway" "pathways in cancer", and "prostate cancer" identified as being overrepresented among the known ARinteracting proteins identified in the N-TAP purifications by the bioinformatics tool "DAVID" and "g-profiler". Listed are the interacting proteins that were unique for the proliferating cells (33), interacting proteins that were unique for the nonproliferating cells (37), and interacting proteins common to both (common). The AR is bolded.

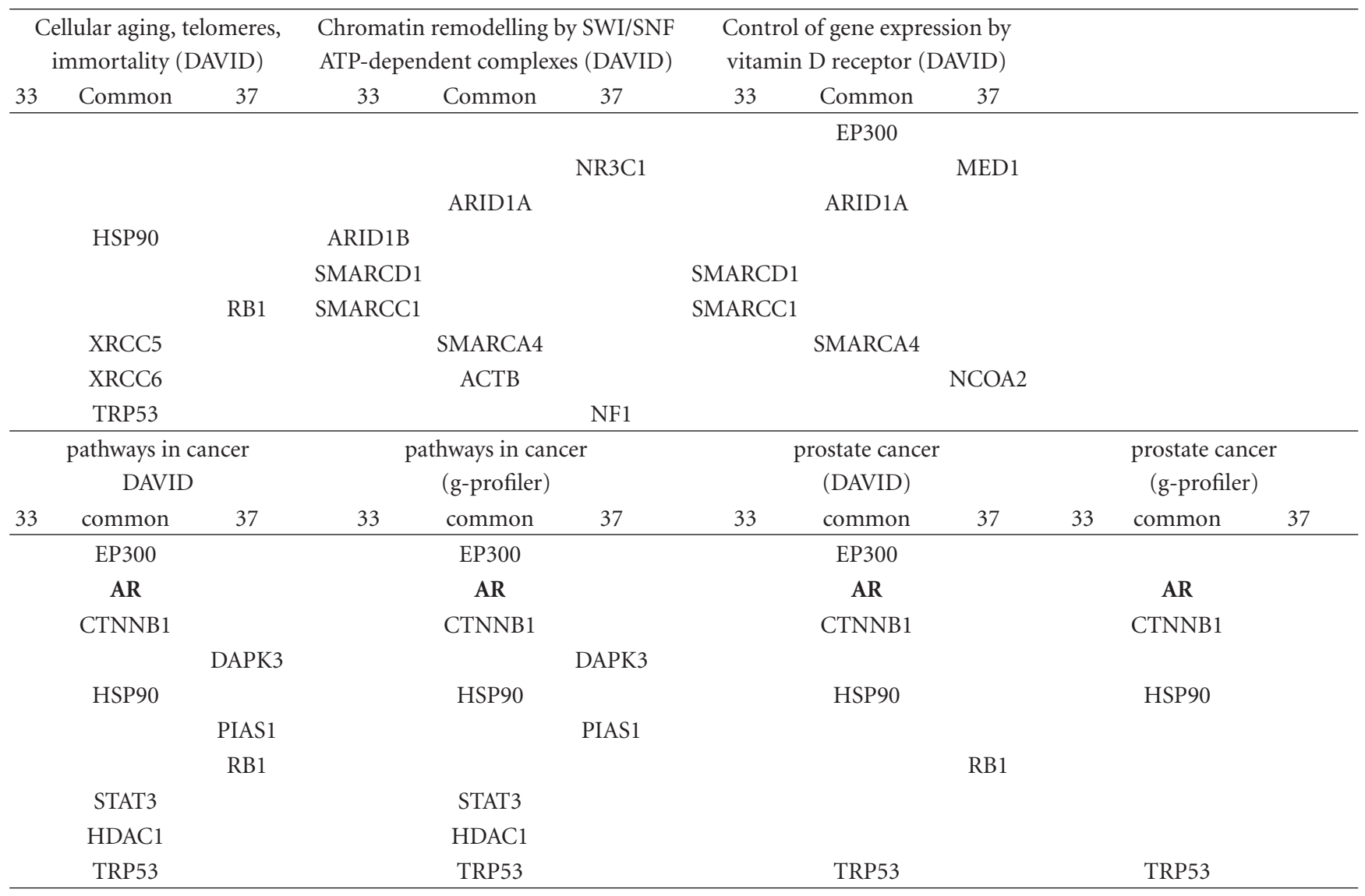

expression" scored high at both temperatures, with many genes overlapping in both categories (Table 2). Also here the Kegg pathway components for prostate cancer are revealed for both temperatures, but only 4 (HSP90, AR, CTNNB1, and TRP53) as shown in Table 3.

$37^{\circ} \mathrm{C}$. Kegg pathway: "pathways in cancer" is only detected in the $37^{\circ} \mathrm{C}$ samples, with 9 components represented (EP300, STAT3, HDAC1, HSP90, AR, CTNNB1, TRP53, DAPK3, and PIAS1). The gene ontology subgroups for "biological processes" (BPs), "anatomical structure morphogenesis", and "embryo development" are overrepresented in the $37^{\circ} \mathrm{C}$ samples and overlapping components are involved (Table 4). "Embryo development" components are NCOR2, AR, CTNNB1, KDM1A, PRKDC, SP1, MED1, SMARCA4, HDAC1, TRP53, TGFB11, PSMC3, and NF1. "Anatomical structure morphogenesis" components are NCOR2, AR, CTNNB1, ACTB, PRKDC, SP1, MED1, SMARCA4, HDAC1, TRP53, TGFB11, GSN, NF1, GATA3, STAT3, NR3C1, and STAT3. Comparison of these 2 groups suggests a more specific function in morphogenesis during embryo development for NR3C1, GATA3, and STAT3 (strong evidence) GSN and ACTB (weak evidence).

$33^{\circ} \mathrm{C}$. Among cellular component profiling, the nBAF complex is solely detected in the $33^{\circ} \mathrm{C}$ samples with SMRCC1, SMARCD1, SMRCA4, and ARID1A (not listed in tables). These proteins are also components of the SWI/SNF chromatin remodelling complex.

3.4. Western Blot Analysis of Cofactors Identified Only in Proliferating or Only in Nonproliferating PC1 Cells. The observation that some AR-interacting proteins were only detectable in proliferating cells and others only in nonproliferating cells (Table 1 ) could simply mean that the quality of the cell extracts varies and much less protein is present in one of the extracts. Another reason might be that expression levels of those proteins alter during cell proliferation, and less or more protein is available for interaction with AR. A third option is that the binding affinity of AR to the interacting proteins changes with the proliferation status of the cells. To address these questions, we carried out Western 
TABle 4: Gene lists for the biological processes (BP) "chordate embryonic development" and "embryo development" found to be overrepresented among the known AR-interacting proteins identified in the N-TAP purifications from the $37^{\circ} \mathrm{C}$ samples but not the $33^{\circ} \mathrm{C}$ samples by the bioinformatics tool "DAVID" and "g-profiler". Listed are the interacting proteins that were unique for the nonproliferating cells (37) and interacting proteins common to both (common). The AR is bolded. AR-interacting proteins identified only in the $33^{\circ} \mathrm{C}$ samples are not involved in biological processes addressed here. No counterpart for the biological process "anatomical structure morphogenesis" could be identified by DAVID.

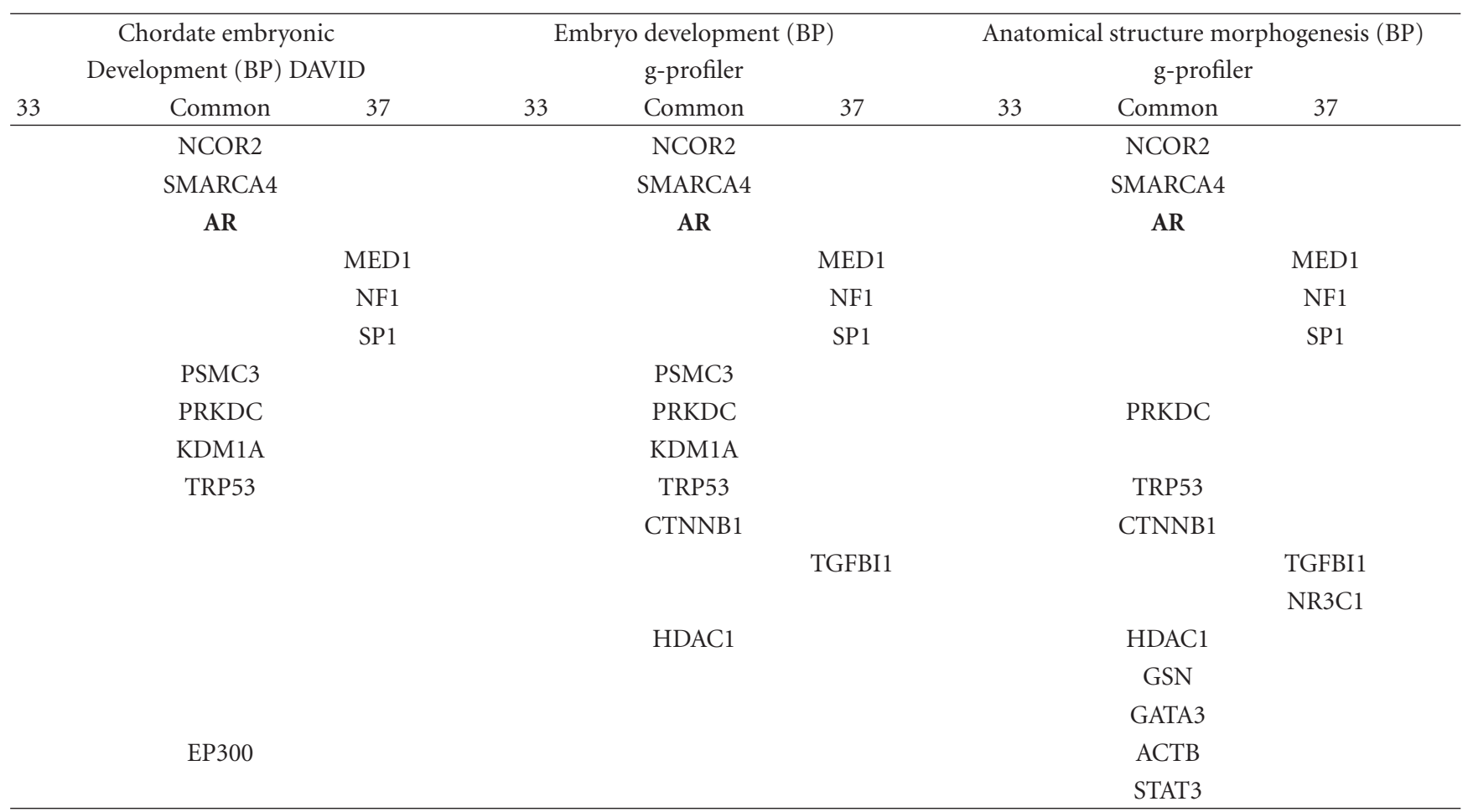

blots, probing those AR-interacting proteins which were differentially expressed (Figure 4).

No major differences in expression were observed when extracts were probed with AR-N20 and ACTB control antibodies, but differences were found elsewhere. NR3C1 is expressed at much higher levels in nonproliferating versus proliferating P17 cells, and expression levels of SMARCC1 were slightly lower in nonproliferating $\left(37^{\circ} \mathrm{C}\right) \mathrm{PC} 1 / \mathrm{P} 17$ when compared to proliferating cells $\left(33^{\circ} \mathrm{C}\right)$. The difference in the amounts of AR copurified SMARCC1 in proliferating versus nonproliferating is not as striking as it is for $\mathrm{NR} 3 \mathrm{Cl}$, and the amounts at "low expression" temperatures are probably too small to be detected by mass spectroscopy. The proliferation status of P17 cells seems to affect SMARCC1 and NR3C1 expression levels per se as SMARCC1 expression is up and NR3C1 expression is down in proliferating cells. However, the loss of NR3C1 expression in proliferating cells is unlikely to account for all the loss in AR binding observed here. Similar loss of SMARCC1 expression in nonproliferating cells does not account for all the loss in AR binding detected. Therefore, expression levels of coregulators and binding affinity to AR may contribute to the differences observed in the $33^{\circ} \mathrm{C}$ and $37^{\circ} \mathrm{C}$ coregulator profiles. The N-TAP$\mathrm{mAR}$ itself appears to increase GR expression levels by at least 3 fold under nonproliferating conditions comparing GR expression in PC1 and P17 input samples (Figure 4).

\section{Discussion}

We have developed the epithelial and mesenchymal mouse cell lines P17 and M7 for copurification of AR-associated protein complexes under native conditions. The two cell lineages are derived from the proximal caput epididymus (P17) and the mesenchyme of the fetal vas deferens (M7) of the mouse. The decision to carry out preparative scale N-TAP-mAR purification on PC1 cells rather than MFVD cells was based on the observation that CTNNB1 and SRC-1 could not be copurified from MFVD cells with our extraction protocol, whereas in P17 copurifications both coactivators were easily detected. Another advantage of choosing the PC1 cell line was the more abundant AR expression and the rapid growth compared to the mesenchymal cells. One confluent dish of PC1 gave about 5-10 times as much cell pellet than 1 confluent dish of MFVD.

To demonstrate proof of principle we used the newly developed purification protocol to detect differences in AR cofactor binding in cells grown under proliferating $\left(33^{\circ} \mathrm{C}\right)$ and nonproliferating $\left(37^{\circ} \mathrm{C}\right)$ conditions. As expected, many of the copurified proteins confirm the role of the AR in chromatin remodelling machinery, transcriptional complexes and associated with the cytoskeleton. The purification protocol we use is relatively crude and results in enrichment of 200-500 bp DNA fragments after a micrococcal nuclease 


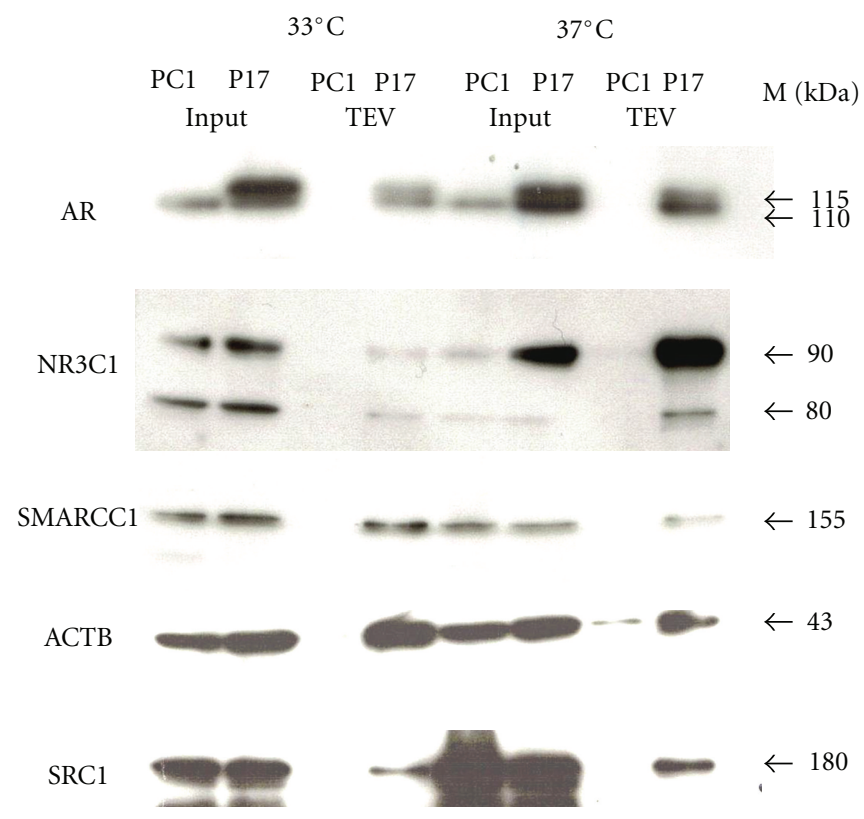

FIGURE 4: AR interacting proteins SMARCC1 and NR3C1 are differentially expressed in proliferating versus nonproliferating P17 cells. Western blot analysis of known AR coregulators identified by mass spectrometry only in AR FLAG copurifications from proliferating P17 cells (SMARCC1) and of a known coregulator identified by mass spectrometry only in AR FLAG copurifications from nonproliferating P17 cells (NR3C1). SRC1 was not identified at all, neither in purifications from proliferating nor nonproliferating P17 cells. AR and ACTB were identified in both FLAG copurifications from P17 cells by mass spectrometry. Compared to the other identified known AR interacting proteins NR3C1, SMARCC1, and ACTB, a smaller portion of the total SRC1 present in the nuclear extract (P17 Input) interacts with AR (P17 TEV). $\mathrm{M}$ is the size estimate by a prestained protein ladder in kilo Daltons $(\mathrm{kDa})$.

digestion. The isolation protocol is nondenaturing and keeps the chromatin fraction as intact as possible. No size fractionation step is included, which could allow isolation of larger chromatin fractions, especially heterochromatic fractions which are not degraded by micrococcal nuclease. This fraction could contribute to a background of unspecific binding, which is difficult to control for as this might not occur in the PC1 control sample, where the "anchor" in form of the N-TAP-mAR is missing. On the other hand, the purification protocol is selecting for stable interactions, because no cross-linking step is included in our purification procedure.

We have not tested whether novel interacting proteins identified with this approach are indeed associated with AR or whether they are just contaminants. These potential interacting proteins could be novel AR-interacting proteins, but could also bind unspecific to the FLAG-M2-coupled magnetic beads. Unspecific binding to the FLAG antibodycoupled magnetic beads is estimated at $5 \%$ based on the recovery of protein from the FLAG purification of the PC1 control sample. This would mean that 1 out of 20 identified proteins is not part of the AR-associated complex. Unfortunately we were not able to reduce this background with an additional His purification step, because the FLAG purified and protease (TEV) eluted fraction was not able to specifically bind Nickel resin, probably caused by complex components covering up the His tag. In this study we concentrate only on a small proportion of all the potential
AR-binding partners identified, representing the already known AR-interacting proteins. We show that our approach has the potential to differentiate between proteins which preferably form part of the AR complexes in proliferating or nonproliferating conditions, and those proteins where interaction is independent of the proliferation status of the cells.

4.1. Functional Enrichments among the Known AR Cofactors Identified with Two Different Bioinformatics Resources. Common pathways enriched for or overrepresented in proliferating and nonproliferating AR FLAG purifications were the biological processes "transcriptional regulation" and "gene expression". Considering that the androgen receptor is classified as a transcription factor, high scores in those categories are expected. Scoring surprisingly high were BIOCARTA pathways not involving AR at all such as "chromatin remodelling by hSWI/SNF ATP-dependent complexes" and "control of gene expression by vitamin D receptor (VDR)" (Figure 5), which involves the WINAC chromatin-remodelling complex. Both WINAC and SWI/SNF complexes have BAF components (Brg1associated factors). The requirement of the BAF complexes has been shown in vitro for ligand-dependent transactivation by nuclear hormone receptors, such as vitamin D3 receptor, retinoid $\mathrm{X}$ receptor, and peroxisome proliferatoractivated receptor PPAR- $\gamma$ [16]. It has also been shown in vivo for reconstitution of glucocorticoid-receptor-(NR3C1-) 
At $33^{\circ} \mathrm{C}$ AR competes for 5 WINAC components and transcriptional activator EP300 of vitamin D receptor-mediated transcriptional activation:

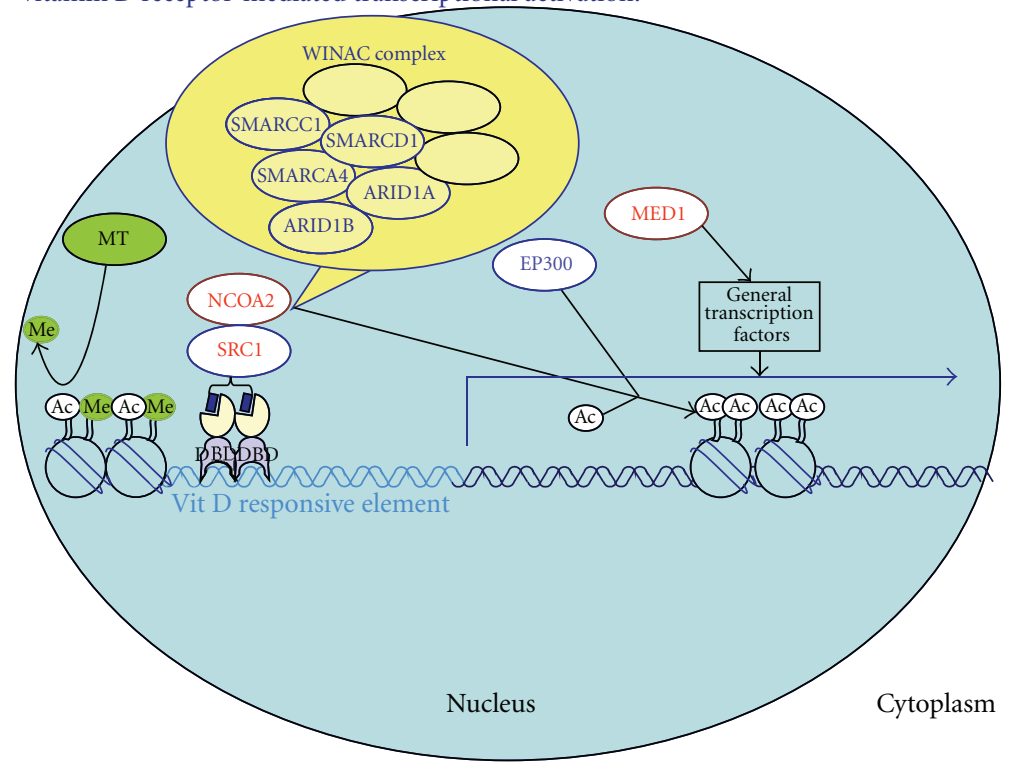

(a)

At $37^{\circ} \mathrm{C}$ AR competes for 2 WINAC components and 4 transcription activation factors of vitamin D receptor-mediated transcriptional activation:

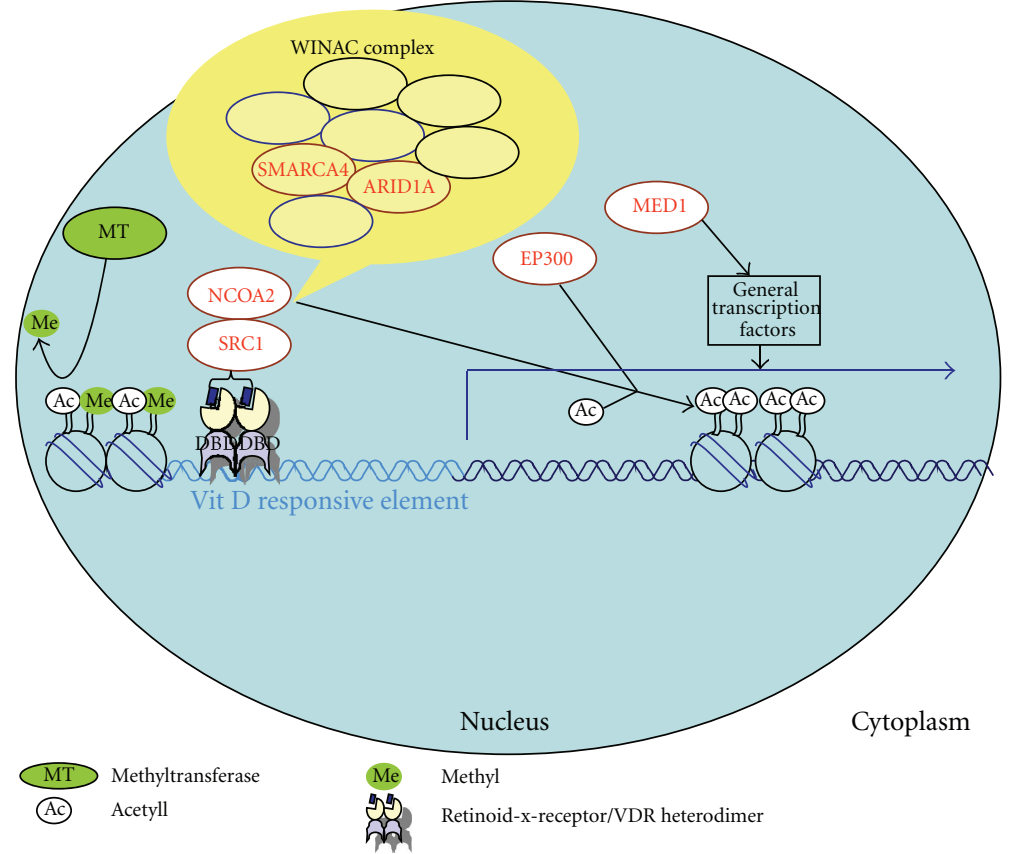

(b)

FIGURE 5: AR-interacting proteins are WINAC complex components and transcriptional activators of VDR-mediated gene expression. Presented is a simplified version of the BIOCARTA pathway "control of gene expression by Vitamin D receptor (VDR)" illustrating how $\mathrm{AR}$ and VDR may compete for shared coregulators. (a) In AR copurifications from proliferating P17 cells $\left(33^{\circ} \mathrm{C}\right)$, the transcriptional activators EP300, SRC1*, and 5 proteins from the ATP, dependent chromatin remodelling complex WINAC: SMARCA4, ARID1A, ARID1B, SMARCC1, and SMARCD1 were identified. Under proliferating conditions, AR would therefore compete with VDR for 5 WINAC components and for 2 transcriptional activators. (b) In copurifications from nonproliferating P17 cells ( $\left.37^{\circ} \mathrm{C}\right)$ only 2 known AR-interacting proteins identified were components from the WINAC complex: SMARCA4 and ARID1A. However, 4 proteins identified: EP300, NCOA2, MED1, and SRC1* act as transcriptional activators in VDR, mediated gene expression. Under nonproliferating conditions, AR would therefore compete with VDR for 2 WINAC components and 4 transcriptional activators. *SRC1 is a general transcription activator for steroid receptors and also component of this pathway. SRC1 was not identified by mass spectrometry, but AR-associated in Western blots of FLAG-purifications from nuclear extracts of proliferating and nonproliferating P17 cells (Figures 4 and 3(b)). 
dependent transcription [17], chromatin remodelling on interferon and virus inducible genes [18] and in neural development with a subunit switch in the npBAF (neural progenitors-specific) chromatin remodelling complex, essential for the transition from neural stem/progenitors to postmitotic neurons [19] but has never been associated with AR. Also the Vitamin D3 receptor has not been identified as AR-interacting protein neither in our purification (data not shown) nor by others. It is however possible that AR transactivation might be stimulated by components of the WINAC complex. The VDR and the AR could therefore compete for shared coregulators, which would explain the observation that AR stimulation by androgens suppresses VDR [20, 21], while AR downregulation by siRNA stimulates VDR levels in LnCAP cells [21]. WINAC complex components might be potential coplayers in AR transactivation, which could be tested with siRNA cotransfection experiments in our cell line. G-profiler, which does not offer a tool such as the BIOCARTA, also identified BAF components as being overrepresented. Another overrepresented pathway is the prostate cancer pathway, which is picked up by both bioinformatics tools. G-profiler does not identify EP300 as a gene involved in prostate cancer as it is done by DAVID (Table 3 bottom). Also the "Kegg cancer pathway" is picked up by both bioinformatics tools: g-profiler identifies the same list of genes among the known AR-interacting proteins as "DAVID", only that RB1 is not included in the g-profiler gene list (Table 3 bottom).

For male genital development and PAIS relevant biological processes are "embryo development", which is here represented with 13 genes identified by g-profiler and 11 identified by DAVID. Of those 10 are overlapping (Table 4). The embryonic genes identified by DAVID are restricted to chordate development and do not include CTNNB1, HDAC1 and TGFBI1, although CTNNB1 and HDAC1 "knock outs" in mouse have been shown to result in developmental phenotypes [22, 23]. G-profiler did not pick up EP300. A role of EP300 in patterning and development was suggested by studies in mice in which EP300 expression was disrupted [24]. Both bioinformatic tools David and gprofiler complemented each other in this study in identifying androgen receptor regulated pathways and biological processes.

In future we aim to replace the endogenous AR with N-TAP-mAR. We will hopefully be able to apply the FLAG purification protocol tested in this study to identify differences in the proteome caused by the respective AR mutation. The protein purification approach taken here and shown to identify differences in co-factor recruitment of AR under proliferating and nonproliferating conditions is encouraging to undertake further experiments aiming to identify specific interaction protein profiles for AR mutants associated with PAIS.

\section{Conflict of Interests}

The authors declare that they have no competing interests.

\section{Acknowledgments}

This work was supported by EuroDSD Collaborative Project funded by the European Commission under the 7th framework Programme and by the NIHR Cambridge Biomedical Research Centre. The authors thank Trevor Bunch, Karolina Zielińska, Rieko Tadokoro, and Vickie PilfoldWilkie for technical assistance and helpful comments and Helga Grötsch and Ralf Werner for valuable discussions.

\section{References}

[1] J. Jaaskelainen, A. Deeb, J. W. Schwabe, N. P. Mongan, H. Martin, and I. A. Hughes, "Human androgen receptor gene ligand-binding-domain mutations leading to disrupted interaction between the N- and C-terminal domains," Journal of Molecular Endocrinology, vol. 36, no. 2, pp. 361-368, 2006.

[2] I. A. Hughes, B. A. J. Evans, R. Ismail, and J. Matthews, "Complete androgen insensitivity syndrome characterized by increased concentration of a normal androgen receptor in genital skin fibroblasts," Journal of Clinical Endocrinology and Metabolism, vol. 63, no. 2, pp. 309-315, 1986.

[3] S. Kerkhofs, S. Denayer, A. Haelens, and F. Claessens, "Androgen receptor knockout and knock-in mouse models," Journal of Molecular Endocrinology, vol. 42, no. 1, pp. 11-17, 2009.

[4] Y. Araki, K. Suzuki, R. J. Matusik, M. Obinata, and M. C. Orgebin-Crist, "Immortalized epididymal cell lines from transgenic mice overexpressing temperature-sensitive simian virus 40 large T-antigen gene," Journal of Andrology, vol. 23, no. 6, pp. 854-869, 2002.

[5] A. Umar, T. M. Luider, C. A. Berrevoets, J. A. Grootegoed, and A. O. Brinkmann, "Proteomic analysis of androgen-regulated protein expression in a mouse fetal vas deferens cell line," Endocrinology, vol. 144, no. 4, pp. 1147-1154, 2003.

[6] D. W. Huang, B. T. Sherman, and R. A. Lempicki, "Systematic and integrative analysis of large gene lists using DAVID bioinformatics resources," Nature Protocols, vol. 4, no. 1, pp. 44-57, 2009.

[7] D. W. Huang, B. T. Sherman, and R. A. Lempicki, "Bioinformatics enrichment tools: paths toward the comprehensive functional analysis of large gene lists," Nucleic Acids Research, vol. 37, no. 1, pp. 1-13, 2009.

[8] J. Reimand, M. Kull, H. Peterson, J. Hansen, and J. Vilo, "g:Profiler-a web-based toolset for functional profiling of gene lists from large-scale experiments," Nucleic Acids Research, vol. 35, pp. W193-W200, 2007.

[9] E. Fernández, M. O. Collins, R. T. Uren et al., "Targeted tandem affinity purification of PSD-95 recovers core postsynaptic complexes and schizophrenia susceptibility proteins," Molecular Systems Biology, vol. 5, article 269, 2009.

[10] S. Seenundun and B. Robaire, "Time-dependent rescue of gene expression by androgens in the mouse proximal caput epididymidis-1 cell line after androgen withdrawal," Endocrinology, vol. 148, no. 1, pp. 173-188, 2007.

[11] N. Yanai, M. Suzuki, and M. Obinata, "Hepatocyte cell lines established from transgenic mice harboring temperaturesensitive simian virus 40 large T-antigen gene," Experimental Cell Research, vol. 197, no. 1, pp. 50-56, 1991.

[12] E. Saade, U. Mechold, A. Kulyyassov, D. Vertut, M. Lipinski, and V. Ogryzko, "Analysis of interaction partners of H4 histone by a new proteomics approach," Proteomics, vol. 9, no. 21, pp. 4934-4943, 2009. 
[13] K. Nishimura, H. J. Ting, Y. Harada et al., "Modulation of androgen receptor transactivation by gelsolin: a newly identified androgen receptor coregulator," Cancer Research, vol. 63, no. 16, pp. 4888-4894, 2003.

[14] R. Jasalava, H. Martinez, J. Thumar et al., "Identification of putative androgen receptor interaction protein modules: cytoskeleton and endosomes modulate androgen receptor signaling in prostate cancer cells," Molecular and Cellular Proteomics, vol. 6, no. 2, pp. 252-271, 2007.

[15] G. Pottiez, N. Haverland, and P. Ciborowski, "Mass spectrometric characterization of gelsolin isoforms," Rapid Communications in Mass Spectrometry, vol. 24, no. 17, pp. 2620-2624, 2010.

[16] B. Lemon, C. Inouye, D. S. King, and R. Tjian, "Selectivity of chromatin-remodelling cofactors for ligand-activated transcription," Nature, vol. 414, no. 6866, pp. 924-928, 2001.

[17] K. W. Trotter and T. K. Archer, "Reconstitution of glucocorticoid receptor-dependent transcription in vivo," Molecular and Cellular Biology, vol. 24, no. 8, pp. 3347-3358, 2004.

[18] K. Cui, P. Tailor, H. Liu, X. Chen, K. Ozato, and K. Zhao, "The chromatin-remodeling BAF complex mediates cellular antiviral activities by promoter priming," Molecular and Cellular Biology, vol. 24, no. 10, pp. 4476-4486, 2004.

[19] J. Lessard, J. I. Wu, J. A. Ranish et al., "An essential switch in subunit composition of a chromatin remodeling complex during neural development," Neuron, vol. 55, no. 2, pp. 201215, 2007.

[20] H. J. Ting, B. Y. Bao, C. L. Hsu, and Y. F. Lee, "Androgenreceptor coregulators mediate the suppressive effect of androgen signals on vitamin D receptor activity," Endocrine, vol. 26, no. 1, pp. 1-9, 2005.

[21] B. Mooso, A. Madhav, S. Johnson et al., "Androgen receptor regulation of vitamin D receptor in response of castrationresistant prostate cancer cells to $1 \alpha$-hydroxyvitamin D5: a calcitriol analog," Genes and Cancer, vol. 1, no. 9, pp. 927-940, 2010.

[22] K. K. Mak, M. H. Chen, T. F. Day, P. T. Chuang, and Y. Yang, "Wnt $/ \beta$-catenin signaling interacts differentially with Ihh signaling in controlling endochondral bone and synovial joint formation," Development, vol. 133, no. 18, pp. 36953707, 2006.

[23] G. Lagger, D. O’Carroll, M. Rembold et al., "Essential function of histone deacetylase 1 in proliferation control and CDK inhibitor repression," The EMBO Journal, vol. 21, no. 11, pp. 2672-2681, 2002.

[24] L. H. Kasper, F. Boussouar, P. A. Ney et al., "A transcriptionfactor-binding surface of coactivator p300 is required for haematopoiesis," Nature, vol. 419, no. 6908, pp. 738-743, 2002. 


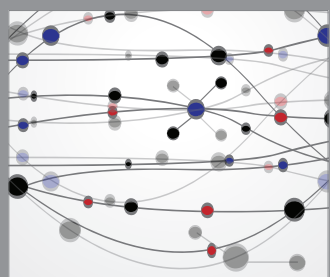

The Scientific World Journal
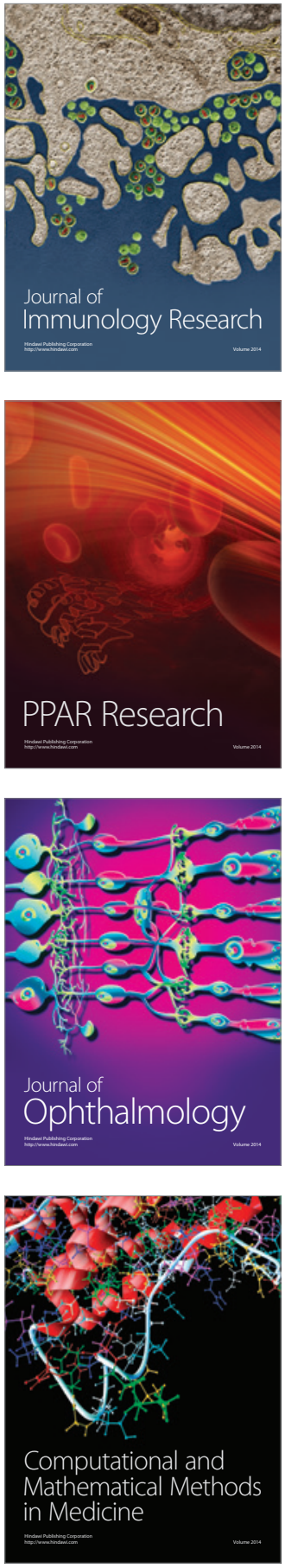

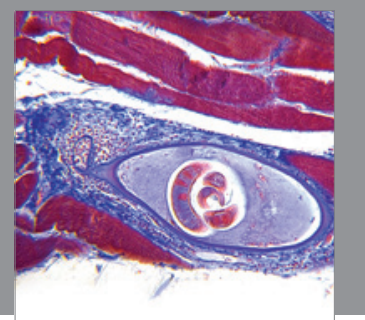

Gastroenterology

Research and Practice
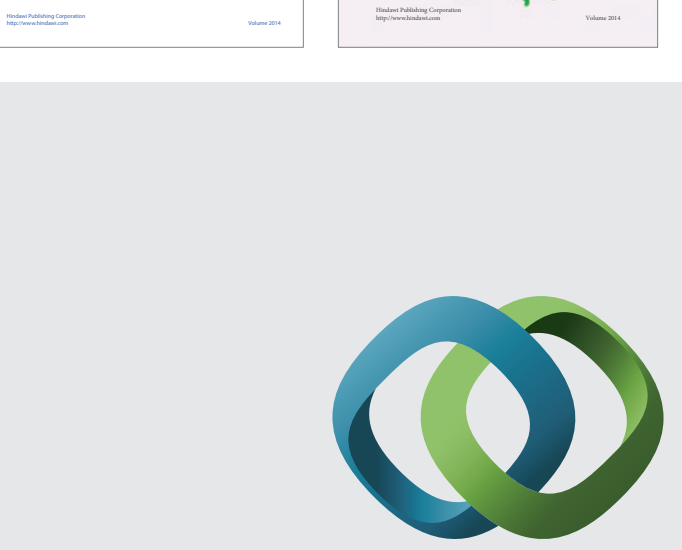

\section{Hindawi}

Submit your manuscripts at

http://www.hindawi.com
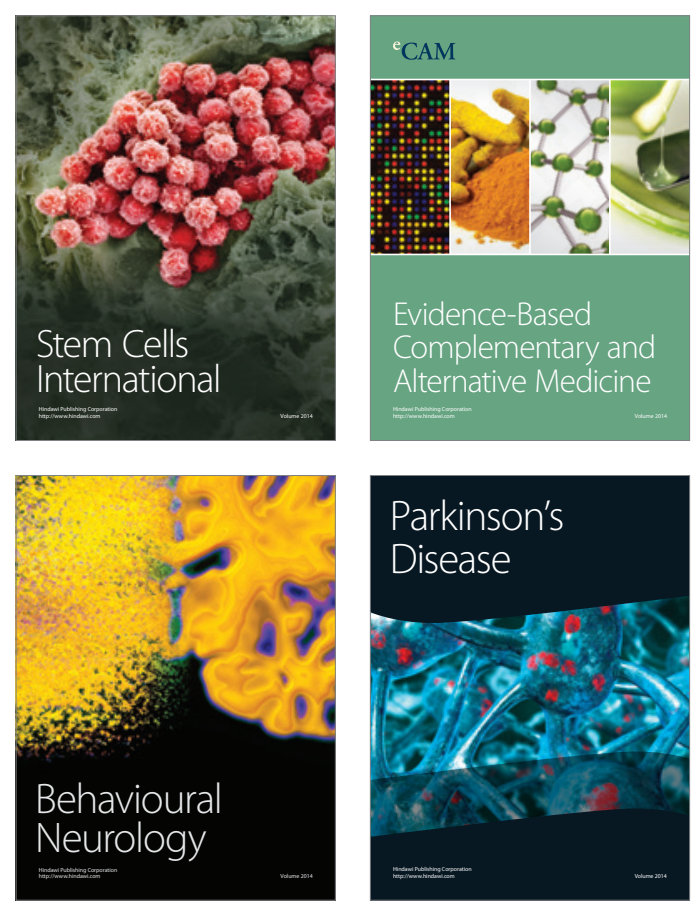

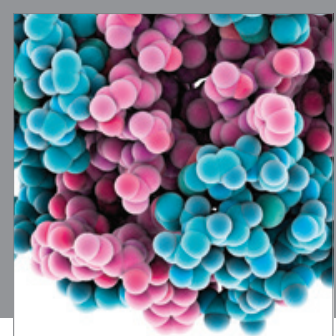

Journal of
Diabetes Research

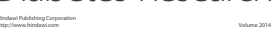

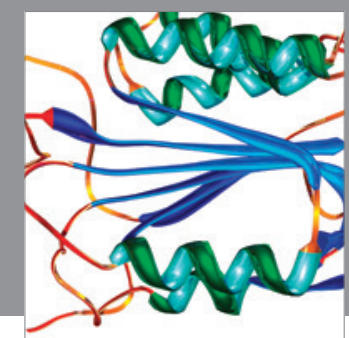

Disease Markers
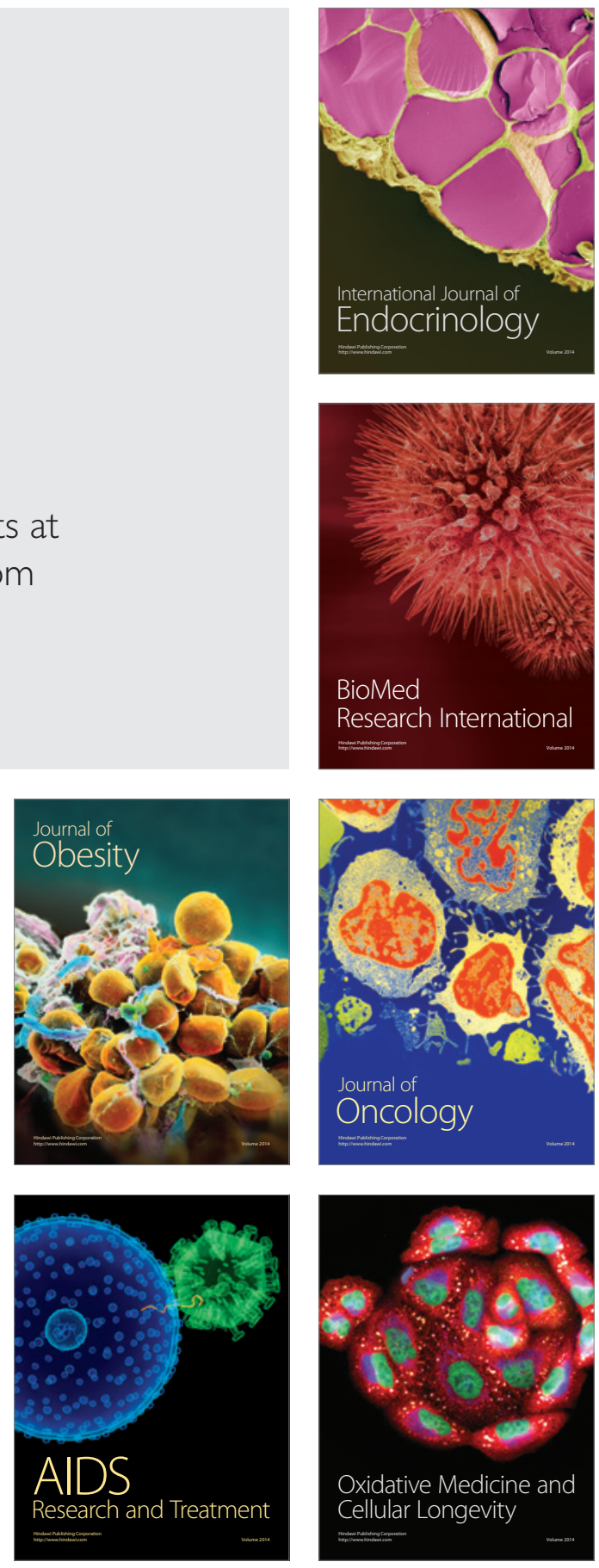